\title{
One-Dimensional Analysis and Modeling of the Xu 7 Engine Due to Changes in Valve Timing to Improve Engine Performance
}

\author{
Mohammad Hassan Kamyab ${ }^{1}$, Amin Moslemi Petrudi ${ }^{1}$, Ionut Cristian Scurtu ${ }^{2}$ \\ 1 Department of Mechanical Engineering, Tehran University, Iran \\ 2 Naval Academy Mircea cel Batran Constanta \\ Email:mohammadhkamyab@gmail.com
}

\begin{abstract}
The advancement of technology and the upgrade of internal combustion engines, the need to use precision and efficiency in controlling and regulating the injection and refuelling sets of the engine has intensified. Proper adjustment of valve timing and ignition is effective in improving the performance of internal combustion engines. In this study, the one-dimensional model of the xu 7 engine was used in the GT Suite software and the effects of changing the timing of the valve on the performance of the engine were investigated. Then, by changing the range of the user's required velocity, the appropriate valve timing was examined. By adjusting the timing of the valve, more power and torque can be obtained in the range of unusual engine velocity's, and the efficiency of the engine can be determined in different types of uses. The extracted engine simulation results are designed for medium velocity's.
\end{abstract}

Keyword: Internal Combustion Engine, XU 7, Engine Operating Range, GT Suite Software, Modelling.

\section{Introduction}

The ability to change the timing of valves for diesel and gasoline engines has been studied by many researchers in a wide range of engine operating conditions [1]. In gasoline engines, the purpose of the valve timing changes is to improve torque at different velocity's in the operation of the entire engine load, and in low loads to reduce fuel consumption. However, most engine researchers have concluded that closing the inlet valve is the most important time to improve engine performance [2]. In designing and optimizing the engine, the design and determination of the system parameters in theory and then applying it to the real engine system and examining the behavior of the system in relation to the applied changes. This method greatly increases the cost and time of product development, because in order to predict the application of any change, it must be implemented in the early stages on the real system and the result must be investigated. At this stage, you can first check the desired changes on the virtual model and thus save time and money. With the complexity of engines and the increase in design parameters in them, this issue has become even more important. As a result, various engine models, including steady flow engines and CFD simulators, are used by engine manufacturers. Each of these models is used according to the characteristics of the car and has a specific range of application, and based on the desired accuracy and complexity, the model structure and modeling method is selected. In this study, the internal combustion engine modeling of XU7 is investigated using modeling in GT power software and then by changing its valve timing in different engine velocity's, the effect of valve timing changes on power diagrams and engine torque is investigated. This is one of the goals of engine modeling [3,4]. The work of various researchers in this field was investigated, the most important of which can be summarized in the table below. Analyzing the topics of 
previous authors who have been involved in the field of knowledge by simulating and numerically solving internal combustion engines in 2019 and 2020, among 1117 ISI articles in the Web of Science (WOS) database. This scientific map was created using vosviewer science software. This software is a scientific tool for studying and analyzing the studies of previous researchers in a specific field of knowledge. The results of the analysis show that the numerical solution and modeling of internal combustion engines have been considered by researchers in recent years. Numerical and parametric solution issues have been among the most important topics among other authors between 2020 and 2019. In this study, the one-dimensional model of the xu 7 engine was used in the GT Suite software and the effects of changing the timing of the valve on the performance of the engine were investigated. In order to improve the performance of the $\mathrm{xu} 7$ engine due to the changes in the timing of the valve, a numerical and one-dimensional analysis of the mentioned engine in GT Suite software was performed. By simulating the engine and implementing engine modeling in GT Suite software, it is possible to determine the appropriate valve timing.

Table 1: Studies on Numerical Analysis and Modeling of Internal Combustion Engines

\begin{tabular}{|c|c|c|c|c|}
\hline Researcher & Modeling method & Output & Input & Year \\
\hline Van et al [5]. & $\begin{array}{l}\text { Semi-experimental use of } \\
\text { interpolation tables }\end{array}$ & $\begin{array}{r}\text { Volumetric } \\
\text { efficiency }\end{array}$ & $\begin{array}{l}\text { Time to inlet valve opens, } \\
\text { Time to outlet valve closes }\end{array}$ & 2001 \\
\hline Golcu et al [6]. & Experimental, neural network & $\begin{array}{l}\text { Torque and } \\
\text { fuel consumption }\end{array}$ & $\begin{array}{l}\text { Engine speed, the inlet valve } \\
\text { timing }\end{array}$ & 2005 \\
\hline Atashkari et al [7]. & $\begin{array}{c}\text { Experimental, determination } \\
\text { of network structure with } \\
\text { genetic algorithm }\end{array}$ & $\begin{array}{l}\text { Torque and } \\
\text { fuel consumption }\end{array}$ & $\begin{array}{c}\text { Engine speed, the inlet valve } \\
\text { timing }\end{array}$ & 2007 \\
\hline Turin et al [8]. & $\begin{array}{l}\text { Semi-experimental, using the } \\
\text { principles of thermodynamics } \\
\text { and estimating unknown } \\
\text { values using regression }\end{array}$ & $\begin{array}{r}\text { Volumetric } \\
\text { efficiency }\end{array}$ & $\begin{array}{l}\text { Time to close the inlet valve, } \\
\text { time to close the outlet valve, air } \\
\text { pressure manifold }\end{array}$ & 2008 \\
\hline Togun et al [9]. & $\begin{array}{l}\text { Experimental and neural } \\
\text { network }\end{array}$ & $\begin{array}{l}\text { Special torque } \\
\text { and fuel consumption }\end{array}$ & $\begin{array}{c}\text { Gas pedal angle, engine speed, } \\
\text { spark timing }\end{array}$ & 2010 \\
\hline FLardh et al [10]. & Experimental linear regression & $\begin{array}{l}\text { Volumetric } \\
\text { efficiency }\end{array}$ & $\begin{array}{l}\text { the inlet and outlet valves, the } \\
\text { smoke manifold pressure }\end{array}$ & 2010 \\
\hline Kocher et al [11]. & Analytical theory & $\begin{array}{l}\text { Volumetric } \\
\text { efficiency }\end{array}$ & $\begin{array}{c}\text { Time to close the inlet valve, } \\
\text { time to close the outlet valve, air } \\
\text { pressure manifold }\end{array}$ & 2011 \\
\hline Tasdemir et al [12]. & $\begin{array}{l}\text { Experimental, neural and } \\
\text { fuzzy network }\end{array}$ & Torque, power & $\begin{array}{c}\text { Engine speed, inlet valve } \\
\text { opening timing }\end{array}$ & 2012 \\
\hline Smith et al [17]. & $\begin{array}{c}\text { Thermodynamic } \\
\text { analysis }\end{array}$ & Stratified charge & Spark ignition engine & 2018 \\
\hline Ulian et al [18]. & Analysis and theoretical & Thermal influences & Spark-ignition engine & 2018 \\
\hline Ismail et al [19]. & Electrochemical analysis & $\begin{array}{l}\text { Hydroxy }(\mathrm{HHO}) \text { dry } \\
\text { cell }\end{array}$ & Hybrid spark-ignition engine & 2018 \\
\hline Venkatesan et al [20]. & Design and analysis & Emission reduction & Exhaust manifold & 2020 \\
\hline
\end{tabular}




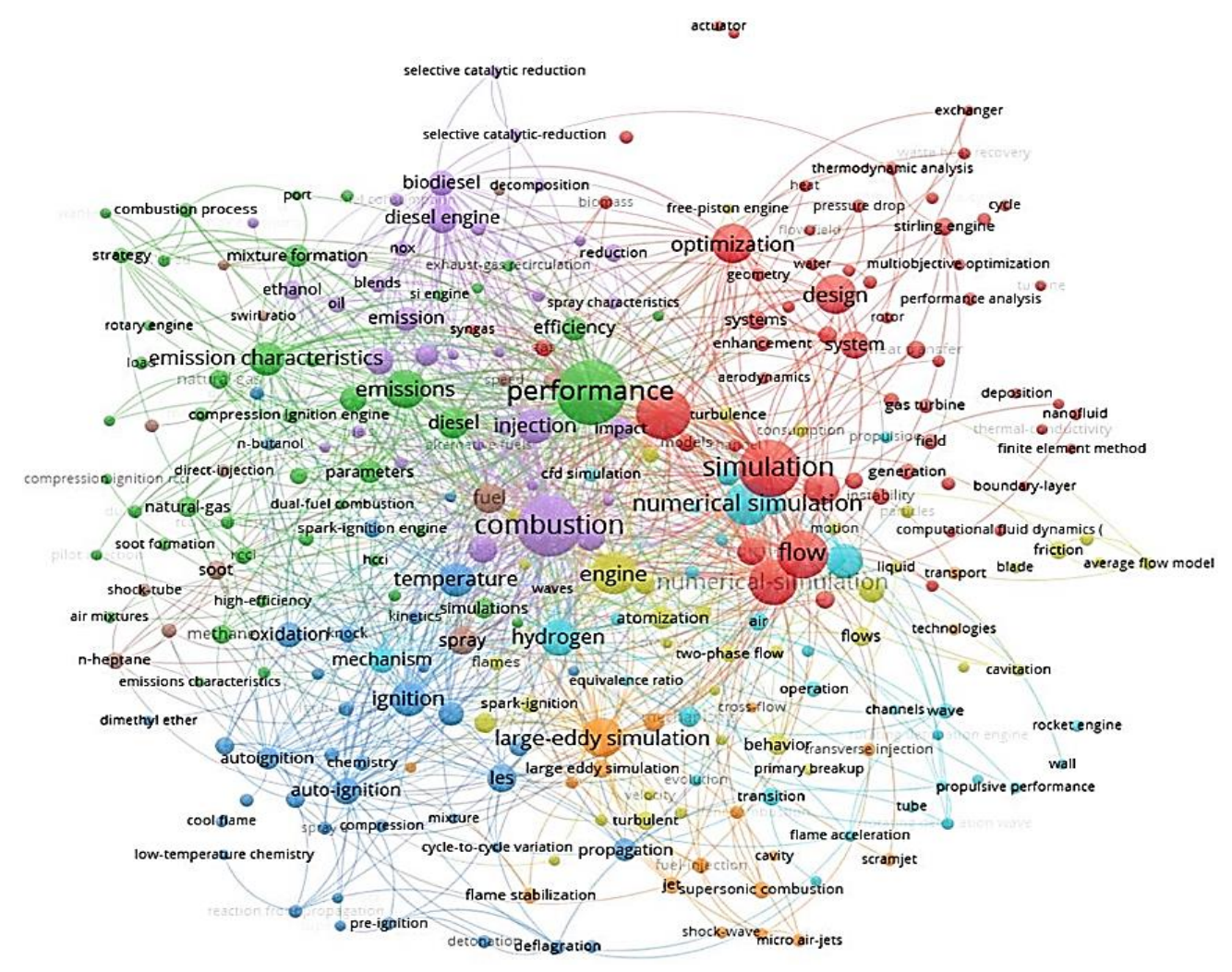

Figure 1. Analyzing previous topics of researchers in the field of internal combustion engines.

The xu7 is a four-stroke, four-cylinder spark ignition engine that is Inline. The cylinder head and cylinder of this engine are cooled by water. This engine is a product of Peugeot company in 2002 and currently this product is used in Peugeot Pars, Samand and Peugeot 405 cars. The xu7 engine is shown in Figure 2.

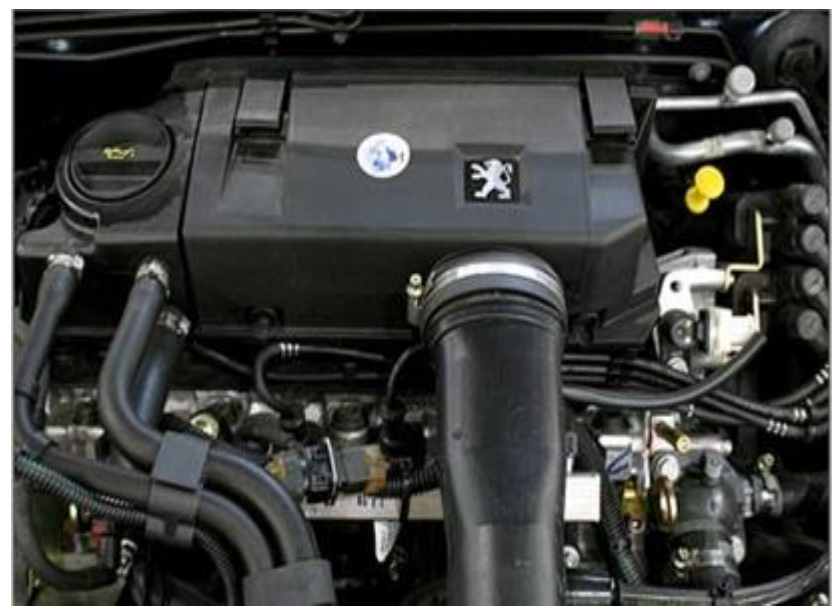

Figure 2. XU7 engine [13].

The existing XU 7 engine series uses an 8-valve multi-point injection system. With a volume of 1,761 liters and a compression ratio of $1: 9,3$. In standard conditions, the engine produces a maximum nominal power of $64 \mathrm{~kW}$ at 6000 RPM. In such cases, the fuel consumption is 5.8 liters per $100 \mathrm{Km}$. The fuel consumption type of lead-free gasoline engine is 85 and 95 octanes. Tables 2 and 3 show the initial specifications of this engine and the time characteristics of injector injection at different velocity's. 
Table 2: General specifications of the XU7 engine [14].

\begin{tabular}{cc}
\hline Value & Parameter \\
\hline 4 & Number of cylinders \\
$8.3 \mathrm{~cm}$ & Cylinder diameter \\
$8.14 \mathrm{~cm}$ & Piston course \\
9.3 & Compression ratio \\
$1.15 \mathrm{~mm}$ & Length of the connecting rod \\
$1800 \mathrm{~cm} 3$ & Nominal displacement volume \\
$11 \mathrm{bTDC}$ & Spark time \\
$64 \mathrm{Kw}$ & Maximum braking power \\
$144 \mathrm{Nm}$ & Maximum brake torque \\
$0.96977 \mathrm{~cm}$ & Maximum inlet valve displacement \\
$0.96977 \mathrm{~cm}$ & Maximum output valve displacement \\
$5.35 \mathrm{bTDC}$ & \\
$3.64 \mathrm{aBDC}$ & Valve timing \\
$61 \mathrm{bBDC}$ & \\
$15 \mathrm{aTDC}$ & Number of cylinders \\
4 & \\
\hline
\end{tabular}

Table 3: Time of injector injection at different velocity's [14].

\begin{tabular}{ccc}
\hline Injection end angle (ATDC) & Injection pulse width & Velocity (RPM) \\
\hline 320 & 230 & 2600 \\
330 & 362 & 3400 \\
330 & 442 & 4200 \\
390 & 531 & 5000 \\
360 & 550 & 6000 \\
\hline
\end{tabular}

\section{Engine modeling in GT Suite software}

Flow modeling involves solving the Navier Stokes (Momentum) equations of continuity and energy. In software, these equations are solved in one dimension. There are two explicit and implicit numerical methods for solving equations. In both cases, the system is divided into small volumes in which all branches will be divided into one subvolume and all pipes will be divided into one volume or more. Scaler variables (such as pressure, temperature, density, internal energy, enthalpy, etc.) are assumed to be uniformly boundary at each of the sub-volumes. Variation variables such as mass flux, velocity, and flux (mass percentage) are calculated for each boundary. The following figure shows the discretization and calculation of variables. Solve the equations in the software and calculate the variables shown in Figure 3.

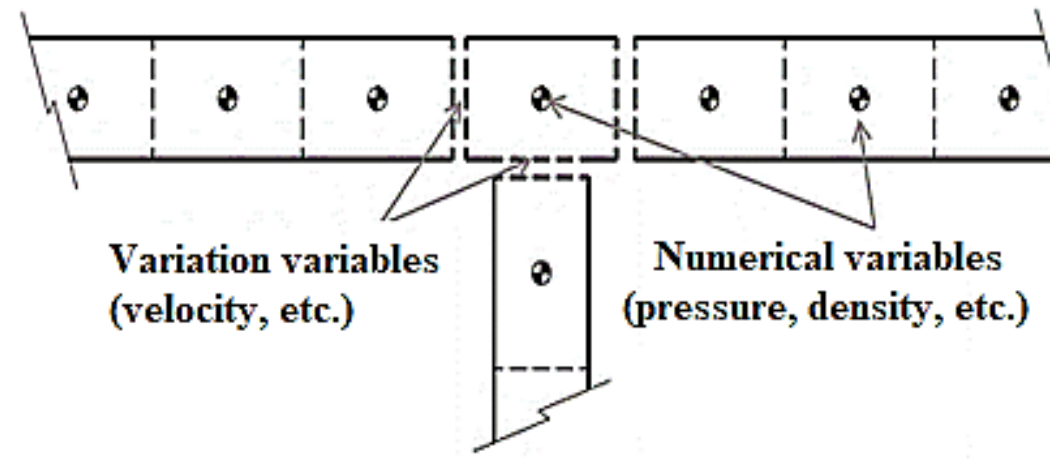

Figure 3. Schematic of discretization and calculation of variables.

Simulation of the engine model in GT Suite software is a good measure of the accuracy between computational load and estimating engine behavior. Due to the number of experiments required for the present problem and the heavy computational load of 3D software, the use of one-dimensional numerical analysis has been used for the work. [15,16] The xu7 motor schematic modeled in GT Suite software is shown in Figure 4. 


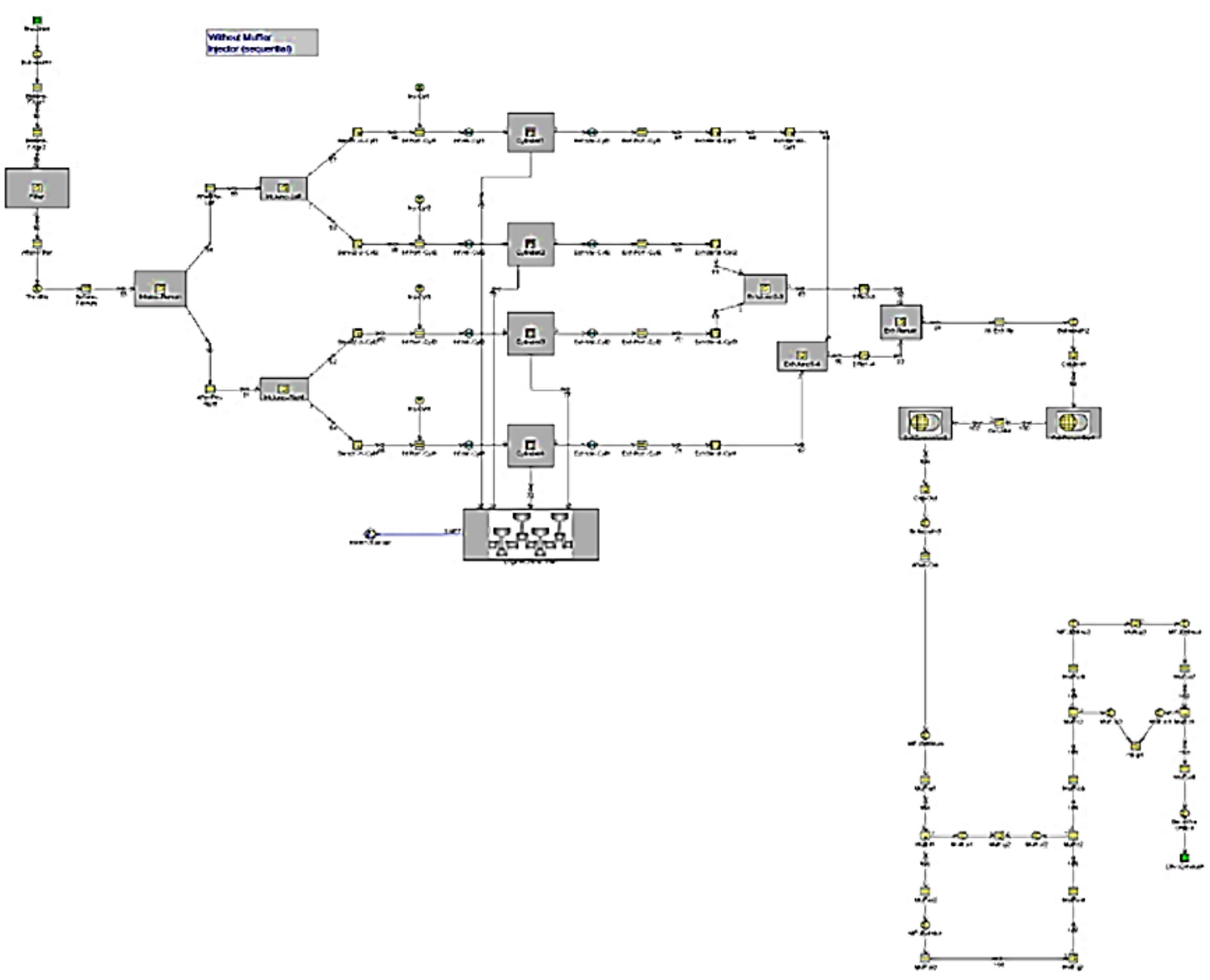

Figure 4. Schematic of xu7 engine simulated in GT Suite software.

\section{Result and Discussion}

The output of the GT POWER software modeling is the behavior of a real motor. And is solved in the steady state. Also, because combustion phenomena and input and output currents are solved in one dimension. All quantities from one point of the flow are considered as the average value of the corresponding quantity in the direction perpendicular to the flow. Leaks from the sides of the compression ring have been avoided. The mixture of air and fuel in the engine is considered homogeneous. The actual conditions of engine input data vary at different times. In this case, with the help of experimental data, modified input data and input data from each round of experimental testing of the engine are measured. Also, through thermodynamic analysis, the initial conditions of different engine velocity's can be predicted more accurately. Because each engine velocity has a different initial temperature and pressure under the conditions created in the intake process. In this paper, the conditions of constant simulation are considered. Laboratory conditions are $88 \mathrm{KPa}$ and a temperature of $20^{\circ} \mathrm{C}$. According to Figures 5 and 6 , in comparing the numerical results of the power and torque of the simulated engine with the experimental results of the mentioned engine in different periods, a good agreement is observed between the numerical and experimental results. So that the maximum deviation of the numerical results of the torque compared to the experimental results is equal to $8 \%$, which occurs in the 1500 RPM mode, and the maximum deviation of the numerical results of the power compared to the experimental results is $9 \%$, which is 2500 RPM it takes. 


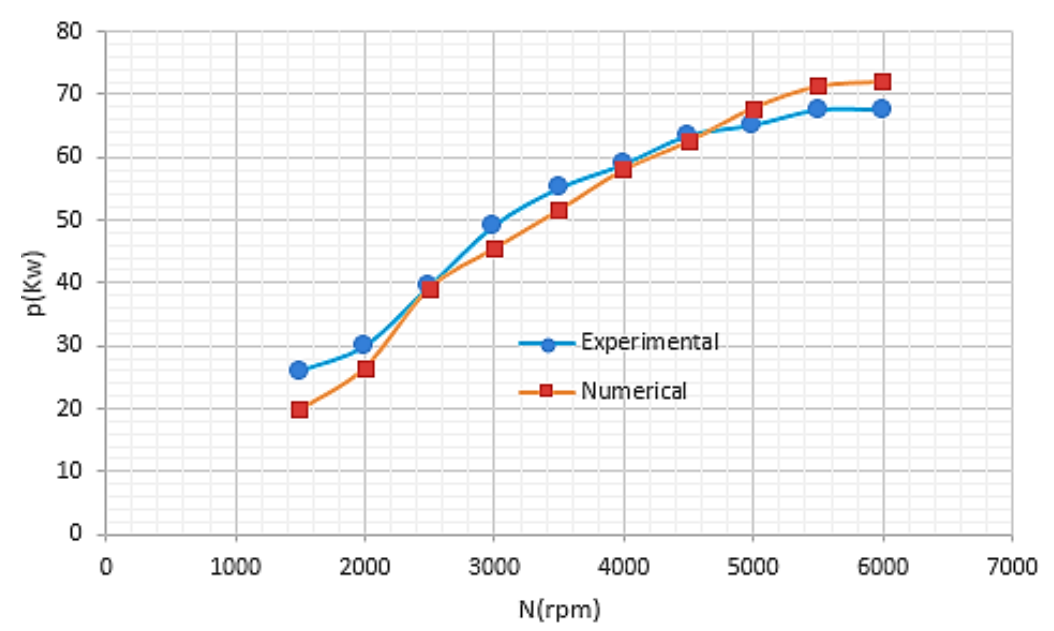

Figure 5. Comparison of numerical results of engine power with experimental results.

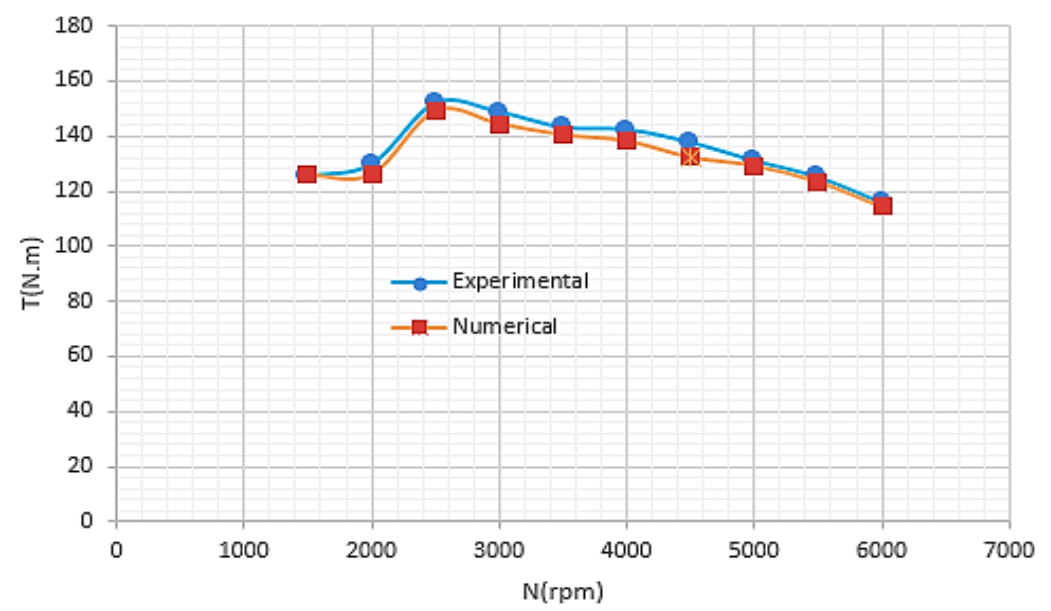

Figure 6. Comparison of numerical engine torque results with experimental results.

The power and torque of the simulated engine have been compared with changing the timing of the valve by $47^{\circ}$ in the inlet valve (Open CA 244) in Figures 6 and 7. According to the diagrams extracted from the software, it was observed that the desired engine is mostly designed for medium velocity's, because due to the valve advance, the power is increased while the engine with its static advance shows more tendency to produce maximum torque. Power and torque increase with advance due to the opening of the valve, it will have enough time to fill the cylinder more, therefore the power increases with increasing the advance and for volumetric efficiency with decreasing timing, the amount of air decreases.

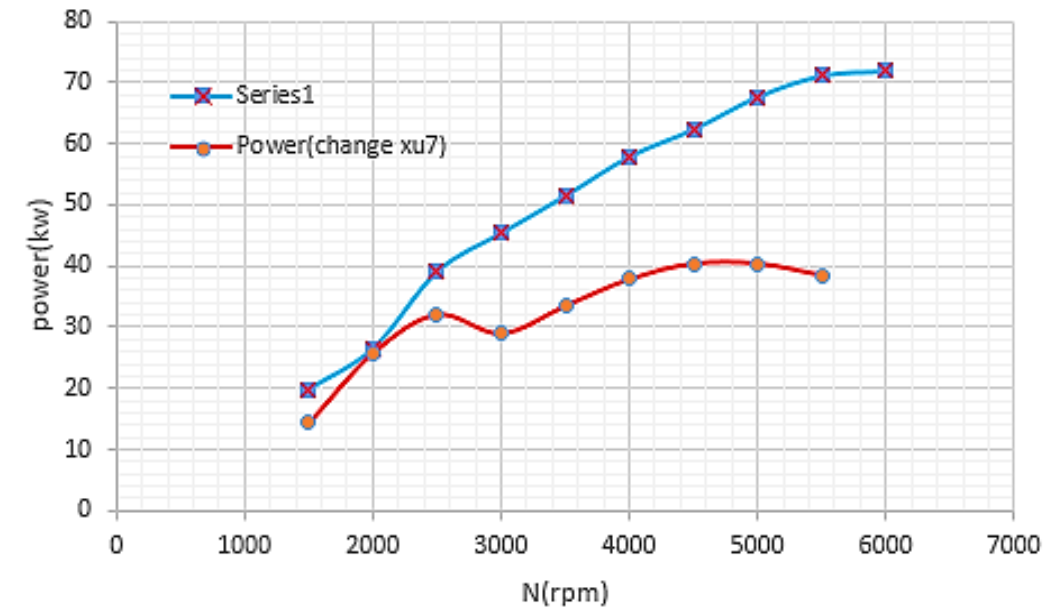

Figure 7. Comparison of power diagram in normal valve timing mode and $47^{\circ}$ change mode in inlet valve. 


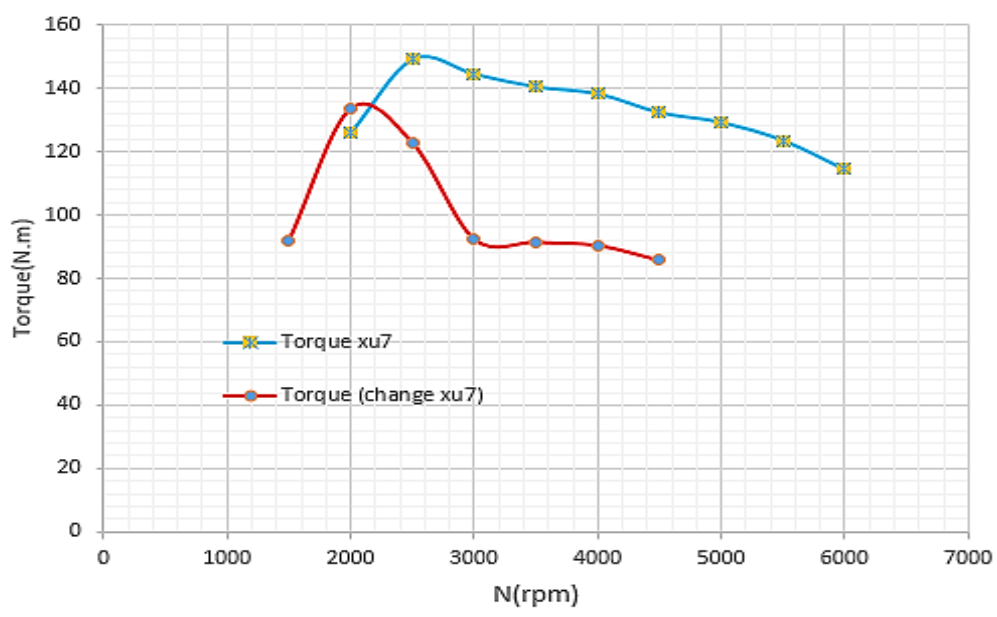

Figure 8. Comparison of torque diagram in normal valve timing mode and $47^{\circ}$ change mode in inlet valve.

\section{Conclusions}

In changing the timing of the valve at different velocity's compared to the initial design mode, the power curve and engine torque are usually reduced. By optimizing and selecting the optimal timing valve, it extracted more power and torque in the range of unusual cycles and provided the appropriate engine performance in the desired uses. The results showed that the engine was designed for medium velocity's. Comparing the results of this method with the work of other researchers shows that this method has a good accuracy.

\section{References}

[1] A. Tafreshi, M. Zissimos. Prediction of Fuel Maps in Variable Valve Timing Spark Ignited Gasoline Engines Using Kriging Metamodels. SAE Technical Paper. No.1 (2020) pp. 01-744. https://doi.org/10.4271/2020-01-0744

[2] B. Rao. Optimization of engine VCR parameters using particle swarm optimization-based desirability approach. World Journal of Engineering, No. 2, (2020) pp. 153-160. https://doi.org/10.1108/WJE-07-2019-0210

[3] Y. Cheng, L. Jingping. Harmonic analysis and optimization of the intake system of a gasoline engine using GT-power. Energy Procedia. (2012): 756-762. https://doi.org/10.1016/j.egypro.2011.12.1007

[4] S. Narayanan, C. Emmanouil, A. Constantinos. Shared autonomous vehicle services: A comprehensive review. Transportation Research: Emerging Technologies 14, (2020) 255-293. https://doi.org/10.1016/j.trc.2019.12.008

[5] N. Van, J. Michiel, U. Fazal. H. John. S. Hashemi. Emission control system. U.S. Patent (2001) 6269,633. https://patents.google.com/patent/US6269633B1/en

[6] M. Gölcü, S. Yakup. E. Perihan. M. S. Salman. Artificial neural-network based modelling of variable valve-timing in a sparkignition engine. Applied Energy 81, no. 2 (2005): 187-197. https://doi.org/10.1016/j.apenergy.2004.07.008

[7] K. Atashkari, N. Nariman, M. Gölcü, A. Khalkhali, A. Jamali. Modelling and multi-objective optimization of a variable valvetiming spark-ignition engine using polynomial neural networks and evolutionary algorithms. Energy Conversion and Management 48, no. 3 (2007): 1029-1041. https://doi.org/10.1016/j.enconman.2006.07.007

[8] T. Raymond, R. Zhang, M. Chang. Systematic model-based engine control design. SAE International Journal of Passenger CarsElectronic and Electrical Systems 1, no. 2008-01-0994 (2008): 413-424. https://doi.org/10.4271/2008-01-0994

[9] T. Kara, S. Baysec. Prediction of torque and specific fuel consumption of a gasoline engine by using artificial neural networks. Applied Energy 87, no. 1 (2010): 349-355. https://doi.org/10.1016/j.apenergy.2009.08.016

[10] F. Oscar, and J. Mårtensson. Nonlinear exhaust pressure control of an SI engine with VGT using partial model inversion. In 49th IEEE Conference on Decision and Control (CDC), (2010) pp. 6433-6438. IEEE. https://ieeexplore.ieee.org/document/5717243

[11] L. Kocher, E. Koeberlein, K. Stricker, D. Alstine, B. Biller. Control-oriented modelling of diesel engine gas exchange. In Proceedings of the 2011 American Control Conference, (2011) pp. 1555-1560.https://ieeexplore.iee.org/abstract/document/5991425

[12] T. Sakir, I. Saritas, M. Ciniviz, N. Allahverdi. Artificial neural network and fuzzy expert system comparison for prediction of performance and emission parameters on a gasoline engine. Expert Systems with Applications 38, no. 11 (2011): 13912-13923. https://doi.org/10.1016/j.eswa.2011.04.198

[13] R. Barzegar, A. Mirizadeh. Three Dimensional Modelling of Combustion Process and Emission Formation in a Spark Ignition Engine. World Applied Sciences Journal 18, no. 7 (2012): 890-895 


\section{[14] https://en.wikipedia.org/wiki/PSA_XU_engine}

[15] R. Vinícius, N. Duarte, A. Santos, C. Eduardo, F. Antonio, F. P. Pujatti. Effects of mixture enplanement in combustion and emission parameters using a flex-fuel engine with ethanol and gasoline. Applied Thermal Engineering 153 (2019): $463-472$. https://doi.org/10.1016/j.applthermaleng.2019.03.012

[16] W. Chaoyi, M. Chen, Y. Jiang. Electronic Control Fuel Injection System Based on GT-POWER and Moto Tron. Procedia engineering 174 (2017): 773-779. https://doi.org/10.1016/j.proeng.2017.01.221

[17] S. Karl, P. Roberts, A. Kountouriotis, D. Richardson, P. Aleiferis, D. Ruprecht. Thermodynamic modelling of a stratified charge spark ignition engine. International Journal of Engine Research 21, no. 5 (2020): 801-810.

https://doi.org/10.1177/1468087418784845

[18] U. Tudor, V. Vornicu, E. Rakosi, S. Talif. Analysis and theoretical modelling of thermal influences on the inlet process for a spark-ignition engine. Procedia Manufacturing 22 (2018): 695-702. https://doi.org/10.1016/j.promfg.2018.03.100

[19] I. Tamer, M. Khaled, E. Elnaghi, T. Mansour, M. N. Abelwhab. Modelling and simulation of electrochemical analysis of hybrid spark-ignition engine using hydroxyl (HHO) dry cell. Energy conversion and management 181 (2019): 1-14.

https://doi.org/10.1016/j.enconman.2018.11.067

[20] S. Venkatesan, S. Ganesan, R. Devaraj, J. Hemanandh. Design and analysis of exhaust manifold of the spark ignition engine for emission reduction. International Journal of Ambient Energy 41, no. 6 (2020): 659-664.

https://doi.org/10.1080/01430750.2018.1484811 